\section{Sciencerark Reserch, Organizition \& Counseling International Journal of Learning and Teaching}

Volume 09, Issue 2, (2017) 317-324

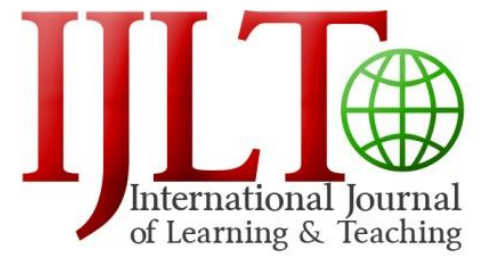

www.ij-lt.eu

\title{
An analytical study of organizational implication in EFL writing experienced by Iranian students with learning difficulties (LD)
}

Yoones Tavoosy*, Faculty of Foreign Languages, University of Isfahan, Hezar Jerib St, Isfahan

\section{Suggested Citation}

Tavoosy, Y. (2017). An analytical study of organizational implication in EFL writing experienced by Iranian Students with learning difficulties (LD). International Journal of Learning and Teaching. 9(2), 317324.

Received November 28, 2016; revised February 21, 2017; accepted April 14, 2017.

Selection and peer review under responsibility of Prof. Dr. Hafize Keser, Ankara University, Ankara, Turkey.

${ }^{\circledR} 2017$ SciencePark Research, Organization \& Counseling. All rights reserved.

\begin{abstract}
This present study concentrates on the organizational implication the Iranian students with learning difficulties (LD) experience when they write an English essay. Particularly, the present study aims at exploring students 'structural problems in EFL essay writing. A mixed method research design was employed including a questionnaire and a semistructured in depth interview. Technical Data Analysis of findings exposed that students experience a number of difficulties in the structure of EFL essay writing. Discussion and implications of these findings are presented respectively.
\end{abstract}

Keywords: Learning difficulties, Iranian students, ESL-EFL students, essay writing, language.

*ADDRESS FOR CORRESPONDENCE: Yoones Tavoosy, Faculty of Foreign Languages, University of Isfahan, Hezar Jerib St, Isfahan.

E-mail address: Tavoosy.ys66@yahoo.com 
Tavoosy, Y. (2017). An analytical study of organizational implication in EFL writing experienced by Iranian Students with learning difficulties (LD). International Journal of Learning and Teaching. 9(2), 317-324.

\section{Introduction}

Students' writing ought to indicate their consciousness of their own Communicative objectives, of the reader, and also of the writing context. Essay writing, which constitutes a problem for many ESL/EFL students widespread, is a foremost challenge for a considerable number of students with learning difficulties (LD). In spite of various attitudes and broad number of approaches to the teaching of writing have evolved from different methods, tackling EFL writing is still one of the most challenging areas for teachers of students with LD. Iranian students with learning difficulties (LD) need to authorize many academic assessments in English. Nonetheless, these students still experience certain obstacles in the organization and organization of their English essay writing as revealed by the results of an introductory essay writing questionnaire administered to fifty students

In Iran yet there have been conducted limited studies in the field of essay writing. The present study is associated with investigating the organizational difficulties that Iranian students with learning difficulties (LD) experience while writing their essays in English.

Iranian students with learning difficulties face particular implication in writing. As many teachers of candidates with LD of English have observed, learning and developing the writing skill seems to be more painstaking and challenging than acquiring the other language skills (Zheng, 1999). The fact of the matter is that generating an effective and well-organized piece of writing is an enormous challenge, particularly in one's second language (Nunan, 1999). This is hugely highlighted by the notion that the rhetorical conventions of English texts-the structure style, and organization-often vary from those in other languages as they necessitate a great effort to identify and manage the difference (Leki, 1991). This is principally true of the rhetorical conventions of the Persian language as candidates' mother tongue

In Iran, the education system gives importance to writing mainly for taking tests. In this respect, several studies in Iran were conducted offering different approaches and remedial programmes to tackle the de-contextualization of writing and to develop candidates' EFL essay writing skills (21).

The present study attempted to find answers to the students with learning difficulties and their teachers perceive the organization of the written essays.

How do Iranian students with learning difficulties (LD) and their teachers perceive the structure of the written essays?

\section{Literature Review}

Writing is "a reflective process and requires time to think about the topic, to analyze and classify background knowledge (Chakraverty \& Gautum, 2000). Writers need to employ an appropriate language to organize these concepts in the form of an efficacious and wellorganized discourse. Writing is an intricate activity, a social act which reflects the writer's communicative skills which is complicated to learn and develop, particularly in an EFL context (Shokrpour \& Fallahzadeh, 2007). L1 writing is perceived as: a cognitive psychological perspective, a socio-cultural perspective and a linguistic perspective (Myhill, 2009). In line with the process writing approach, this paper perceives EFL writing as a multi-dimensional process composed of a cognitive activity affected by a number of linguistic and contextual factors; EFL linguistic proficiency, instructional, psychological, sociocultural, and socio-political issues. If these factors are well-addressed, this will make writing an easy experience. L2 Writing has consistently been regarded a seminal and significant skill in teaching and learning. According to Rao (2007) EFL writing is beneficial in two respects: First, it stimulates students thinking, forming 
Tavoosy, Y. (2017). An analytical study of organizational implication in EFL writing experienced by Iranian Students with learning difficulties (LD). International Journal of Learning and Teaching. 9(2), 317-324.

ideas, and developing their aptitude to summarize, analyze and criticize. Second, it reinforces student learning, thinking and reflecting on the English language.

In regard to the context of the present study, essay writing is substantial to the learning of Iranian students with learning difficulties (LD) since it assists students and teachers' acquisition of the fundamental study skills needed for understanding what they study and expressing it in their own words. This will assist them to evade memorization, rote learning and plagiarism that are much discouraged in the recent theories of teaching learning. Furthermore, aptitude and competence in essay writing will aid students pass their academic courses effectively and also successfully. Likewise, being proficient in essay writing in English will facilitate students with LD and their teachers to be successful teachers and action researchers in the future.

Coherence, or texture, is the combination of semantic configurations of two dissimilar, kinds: register and structure (Halliday \& Hasan, 1985). Text-based features mean structuring (i.e., the linking of sentences) and unity (i.e., being straightforward and sticking to the point). Readerbased features mean that the reader interacts with the text reliant on his/her earlier awareness. Structuring defined as "the organization of discourse with all elements present and fitting together logically" (Heller, 1999). This signifies that a well-organized essay involves an introduction, a thesis statement, rhetorical support, and a conclusion.

A number of research papers across Iran would have illuminated students' organizational problems in English writing. For instance, Arab students' written products revealed that repetition, parallelism, sentence length, lack of variation and misuse of certain cohesive devices are major sources of structure and textual deviation (Qaddumi, 1995). Furthermore, other studies declared that Yemini and Moroccan student writers have some weaknesses, in terms of organization, displayed in the student writers' written texts.

In relation to EFL essay writing organization, numerous researchers come to an agreement that organization, on the instruction level is related to connecting concepts while on the micro level, it is concerned with connecting sentences and phrases. "The concept of organization is a semantic one; it refers to relations of meaning that exist within the text, and that define it as a text" (Halliday \& Hasan, 1985). Many researchers have highlighted the importance of text organization asserting that a text stands as a text by means of organization. But for organization, sentences would be disintegrated and would result in a number of unconnected sentences (Hinkel, 2004).

\section{Method}

In respect of the investigative nature of the present study, and its context-specificity, the interpretive, qualitative research was selected. The interpretive approach will aid the researcher inspect and comprehend the context within which essay writing in English is taught and learnt in typical Iranian upper-intermediate level colleges. This, in turn, will assist the researcher reveal the problems those Iranian students with learning difficulties (LD) and teachers face in the organization of their texts.

The sample of the present study includes fifty students with learning difficulties. Students with learning difficulties were recognized through a check list designed by the researcher. Ten out of fifty students were chosen to be interviewed. Additionally, five teachers filled in the questionnaire and were interviewed to supplement the data and findings. The present study made use of a questionnaire and a semi-structured interview. 
Tavoosy, Y. (2017). An analytical study of organizational implication in EFL writing experienced by Iranian Students with learning difficulties (LD). International Journal of Learning and Teaching. 9(2), 317-324.

\section{Results}

Findings of the present study exposed that students with learning difficulties have to undergo organizational problems in their English writing. In respect to organizational problems in their English writing certain problems were discovered such as difficulty in writing the introduction, the thesis statement, the topic sentence, writing concluding sentences and writing the conclusion. Equally important, the teachers reported that their students have difficulty writing the thesis statement, the topic sentences, transition of notions, and sequence of notions.

A great variety of motives are linked with students' organizational problems in English essay writing. Primarily, the effect of topic-specific background knowledge was seen as effective on the overall quality and local organization of students' writing (Langer, 1983). What is more, it was highlighted that low English proficiency students find it difficult to develop well-organized writing due to paying attention to language matters rather than making meaning (Lee, 2004). Furthermore, this paper supports that students are inclined to observe distinct techniques in their written English that make their writing poorly organized such as including a broad statement in the opening sections of their essays before introducing the topic sentence the same was found with Iranian students with learning difficulties. In addition, Iranian students with learning difficulties overused coordinate sentences and misused topic sentences which were the reasons for their poorly organized and improper quality of writing.

In reference to student problems in organization, some were reported such as difficulty in using cataphoric and anaphoric reference, ellipsis, substitution, and genre related organizational bonds. Besides, overusing certain cohesive bonds was also reported. Varied studies have approved the value of text organization in English writing as a mechanism that expedites discourse flow. These studies also added that constructing well-organized texts by second language learners entails focused instruction and additional attention (Reid, 1993a). Moreover, numerous reviewed studies emphasized that production of well-organized text in English constitutes a serious problem to Iranian students.

\section{Discussion}

The present study exposed in its findings that there are varied and diverse elements and contexts lying behind these organizational problems. In fact, in terms of psychology, students undertake a number of barriers such as lack of incentive, lack of self-assurance, and writing uneasiness.

Iranian students with learning difficulties (LD) are not encouraged to write English essays for more than a few conceivable reasons. First of all, they are taught in a large class characterized by physical as well as intellectual distance between teachers and students. Second of all, Iranian teachers tend to use traditional teaching techniques such as lecturing, reading aloud, and book reading; they are frequently indifferent to student writers' communication in class; and student writers report negative attitudes towards essay writing as a difficult course. These factors are similar to the issues revealed by Holliday, A. (1996) as "sings of boredom", "passive watching" and "teaching spectacle". Lately, it has been referred to the impact of student passive listening on their learning in general and particularly creative writing (Abdollahzadeh, 2010). This lack of enthusiasm can affect negatively on students' improvement in essay writing. Finally, another study has confirmed that students' lack of motivation intensity impact on their vocabulary problems in writing (Al- Akloby, 2001).

Students' low self-esteem could be attributed to a number of socio-cultural issues. Parents' perspective on controlling might be an influential element in students' confidence-rising. As they unintentionally insert a lack of self-confidence in their children by disregarding their opinion in 
Tavoosy, Y. (2017). An analytical study of organizational implication in EFL writing experienced by Iranian Students with learning difficulties (LD). International Journal of Learning and Teaching. 9(2), 317-324.

the family. Students distrust their parents to communicate their thoughts; this ordinarily occurs in the Iranian upbringing context where notable number of parents is potentially willing and ready to reprimand both physically or psychologically their children. Moreover, students habitually have a tendency to ask someone else to assist them in personal activities or school learning tasks. It is common among many Iranian that they depend totally at home on their parents or elder siblings. Individuality and self-reliance in study is an uncommon phenomenon in the Iranian education system and living culture. Another significant factor is parents' unrealistic academic expectation which is beyond some students' intellectual abilities. Regarding the educational system in Iran, students in classroom due to the fear of the teacher's strong authority are not given the opportunity to argue or negotiate with their teachers. All these factors might be the original source of lacking self-confidence among most Iranian students.

Most learning environments at Iranian public high schools or colleges are not designed to elevate student's self-confidence. In fact, it is underscored that writing multiple drafts, putting emphasis on the "publication" of students work, and teachers' comments that focused more on content and organization than on grammatical errors helped them create better pieces of written composition and grow more self-confidence in writing(Tyson, 1997). Similarly, it is claimed that when students are self-possessed in their reading and writing skills, they are able to adjust to new teaching/learning methods quickly (Albertson, 2006).As a result, teachers and colleges must design a mentally reassuring and fostering learning environment in to the Iranian context to develop students' self-reliance and ease their psychological challenges.

Writing tension is said to negatively affect both the learners' incentive (Cheng, 2002) and their academic accomplishment (Macintyre, Noel \& Clement, 1997) on one hand and their outlooks towards writing on the other hand (Atay \& Kurt, 2206). Research has confirmed that high anxious writers, in comparison with other low anxious ones, tend to stop more while writing and are less concerned with planning the overall structure of their essays (Selfe, 1984).

Data exposed a number of features that might have contributed to Iranian students' writing anxiety such as lack of written feedback, undesirable oral reproach, working under time limitation, and about difficult topics for writing. A study across the Iranian context underscored that students with low wrote better quality pieces of written composition and had higher selfesteem than those with high nervousness (Hassan, 1981). Furthermore, it is acknowledged that students' writing anxiety is triggered by their previous negative assessments or by more complex psychodynamics (Rose, 1985). In reference to feedback, it was revealed that the peer feedback group of prospective teachers experienced considerably less writing anxiety than the teacher feedback group as they received opinions from their classmates to elaborate on, and this collaboration assisted them look at their papers differently and lessen their writing anxiety (Rose, 1985). Additionally, it is implied that writer's block that leads to their anxiety in writing may be due to students' writing under time pressure (Lee, 2006). As a final point, it was reported that students with high apprehension selected topics that were more familiar to them and avoided unfamiliar topics (Lee, 2006).

Findings of the current study emphasized that teachers have expressed their concern about their students' lack of reading authentic English texts resulting in substantial challenges with regards to topic prior knowledge, coherence, organization, style, range of vocabulary, and grammatical structures and punctuation. What is more, teachers reported that students normally read the simplified texts of novels and plays. They are not used to reading for long hours and they are not ready to apply that effort. This is likely to impact on English writing because the more one reads the better writing style and vocabulary one develops.

To highpoint how strong and close the relationship between reading and writing should be, it is exploited that the teaching of reading and writing are inseparable (Zheng, 1999) academically, it was recommended that $L 2$ reading would help improve $L 2$ writing at the primary and the higher levels (Bell, 1998). In line with this, it has been confirmed that reading for pleasure and mandatory reading affect developing writing skills positively (Feeris \& Hedgcock, 1998). In 
reference to the Iranian context, the importance of reading to enhance students' previous knowledge was highlighted (El-koumy, 1983). He added that the teaching of reading and writing should be integrated. A few of reasons could be counted for this lack of broad reading, such as lack of motivation from parents, lack of monetary resources, lack of appropriate and wellresourced libraries.

The current study also exposed that Iranian student's lack topic previous knowledge. This was reinforced by the observations of both students as well as their teachers. Accordingly, it was asserted that there is a convincing relationship between topic-specific background knowledge and the quality of student writing (Larios, Marin \& Murphy, 2001). Similarly, previous knowledge and writing experiences appeared to influence on students' revision processes more than any other factors (Selfe,1984). Previous knowledge about written English is thought to be one among other effective factors in students' success (El-Mortaji, 2001).

Rote learning is one of the characteristics exemplifying the Iranian educational system. Students are stimulated to memorize what they study rather than actively take part in serious and generative thinking processes. In cultural terms, Iranian students who memorize what they study are viewed as smarter than those who do not. This is supported by most exams in the diverse educational steps in most courses which ask students questions that mostly require them to evoke what they have memorized in their earlier studies. These exams do not only generate distress and hindrance, but also accentuate rote memorization and restrain critical thinking.

It is widely believed that the Iranian educational system is to evoke competitive learning environment. In an Iranian classroom, students are ranked based on accomplishment that is gained through a grim competition. This has led to teachers constructing some perplexing exams that permit only smart students to pass and necessitate other students to resist several exams or repeat the whole academic year. Consequently, Students contest due to specific socio-cultural factors such as teachers and parents' inspiration.

\section{Implications for Teaching of Writing}

The current study contributes significantly to EFL education in Iranian in terms of English language educational research, and curriculum planning and design. Furthermore, the present study has the potential to develop English language teacher education in several of ways:

a) It highlights the very importance of students' needs as this will facilitate teachers to appreciate ways to find to satisfy these needs and also conduct an effective learning.

b) It functions as a model for further studies in education in terms of using the explanatory constructivist research agenda. This attitude has been entirely overlooked in Iranian and no previous study having used an investigative approach to study the organization and organization problems faced by Iranian students with learning difficulties (LD).

c) It assists curriculum designers take into consideration students' needs and interests in planning their core curriculum.

\section{Conclusion and Recommendations}

- The teaching resources used with Iranian students ought to cover a wide range of organizational skills coping with students; diverse proficiency levels.

- Teaching and learning tasks should be categorized and varied to aid students make the most out of them, in particular, in big classes of different capabilities and skills. 
Tavoosy, Y. (2017). An analytical study of organizational implication in EFL writing experienced by Iranian Students with learning difficulties (LD). International Journal of Learning and Teaching. 9(2), 317-324.

- Essay writing teachers should be educated to employ different classroom interaction techniques and teaching approaches such as pair work and group work, peer-review, student-teacher conferences and any other related techniques. It is also recommended that teachers should be acquainted with using technology in the classroom to help students with different learning styles learn efficiently and rapidly.

- It is recommended that essay writing lecturers should be involved in conducting studies in general and action research in particular where they can discover students' weakness areas and attempt to develop them.

\section{References}

Abdollahzadeh, E. (2010). Undergraduate Iranian EFL learners' use of composing. Strategies. Writing \& Pedagogy, 2(1), 65-90.

Albertson, K. (2006).College Student Perceptions of Expectations for Academic Literacy in Their First Term. (Unpublished PhD Thesis), Indiana University of Pennsylvania, USA.

Atay, D., \& Kurt, G. (2206). Prospective teachers and L2 writing Anxiety. Asian EFL Journal, 8(4), 110-118.

Chakraverty, A., \& Gautum, K. (2000). Dynamics of writing. Forum, 38(3), 1-10.

Cheng, Y. (2002). Factors associated with foreign language writing anxiety. Foreign Language Annals, 35(5), 647-656.

El-koumy, A. (1983). Exploring the reading writing relationship in NES and EFL students ERIC, ED413781. Retrieved from https://papers.ssrn.com/sol3/papers.cfm?abstract id=2364868 on 1 January 2017.

El-Mortaji, L. (2001). Writing ability and strategies in two discourse type: A cognitive study of multilingual Moroccan university students writing Arab (L1) and English (L3) (Dissertation Abstract international), 62(4), C499.

Halliday, M., \& Hasan, R. (1985). Reading-writing connections: From theory to practice. Mahwah, NJ: Lawrence Erlbaum associates.

Hassan, C. (1981). Exploring apprehension: writing processes of apprehensive intermediate freshman writers, ERIC,ED210678. Retrieved from https://eric.ed.gov/?id=ED210678 on 1 January 2017.

Hinkel, E. (2004). "Rehtorical features of text: Cohesion and coherence", teaching academic ESL writing: practical techniques in vocabulary and grammar. Lawrence Erlbaum associates, Mahwah, New Jersey, p.265.

Langer, J. (1983). Effects of topic knowledge on the quality and coherence of informational writing. ERIC, ED234418. Retrieved from https://eric.ed.gov/?id=ED234418 on 1 January 2017.

Larios, J., Marin, J., \& Murphy, L. (2001). A temporal analysis of formulation processes in L1 and L2 writing. Language Learning, 51(3), 497-538.

Lee, C. C. (2004). Seeing is understanding: Improving coherence in students' writing. The Internet TESL Journal, 10(7), 1-4.

Lee, S. (2006). Teaching EFL writing in the university: Related issues, insights, and implications. Journal of National Taipei Teachers College, 16(1), 111-136.

Leki, I. (1991). Twenty-five years of contrastive rhetoric: Text analysis and writing pedagogues. Tesol Quarterly, 25(1), 123-143.

Macintyre, P., Noel S, K., \& Clement, R. (1997). Biases in self-ratings of second languages proficiency: The role of languages anxiety. Language Learning, 47, 265-287.

Myhill, D. (2009). Becoming a designer: trajectories of linguistic development. In Bear, R., Myhill, D., Riley, J., Nystrand, M. The sage handbook of writing development. (pp.402- 13). London: Sage Publications.

Nunan, D. (1999). Second language teaching and learning. Boston: Heinle and Heinle Publishers.

Qaddumi, M. (1995). Textual deviation and coherence problems in the writings of Arag students at the University of Bahrian: Sources and solutions (Unpublished doctorate thesis). University of Nottingham, United Kingdom.

Rao, Z. (2007). Training in brainstorming and developing writing skills. ELT Journal, 61(2), 100-106. 
Tavoosy, Y. (2017). An analytical study of organizational implication in EFL writing experienced by Iranian Students with learning difficulties (LD). International Journal of Learning and Teaching. 9(2), 317-324.

Reid, J. (1993a). Historical perspectives on writing and reading in the ESL classroom. In J. Carson \& I. Leki (Eds.), Reading in the composition classroom: second language perspectives (pp.33-60). Boston: Heinle.

Rose, M. (1985). Complexity, rigor, evolving method, and the puzzle of writer's block: thoughts on writingprocess research. In M. Rose (Ed), when a writer can't write (pp.227-260). NY: Guilford Press.

Selfe, C. (1984). The redrafting processes of four high and four low-apprehensive writers. Research in the Teaching of English, 18(1), 45-64.

Shokrpour, N., \& Fallahzadeh, M. H. (2007). A survey of the students and interns' EFL writing problems in Shiraz University of Medical Sciences. Asian EFL Journal, 9(1), 147-163.

Tyson, R. (1997). Motivation, Self-confidence, and the process Apporach in Korean Univeristy writing classes. Paper presented at the 1997 National Korea TESOL conference, Kyongju.

Zheng, Y. (1999). Providing the students with effective feedback in the writing process. Teaching English in China, 36, 41-45. 